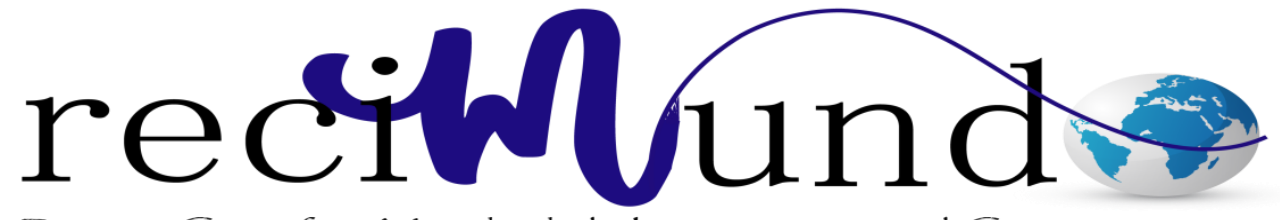

Revista Científica Mundo de la Investigación y el Conocimiento

Nadia del Rocío Campoverde Jiménez ${ }^{\text {a }}$ María de Roció Rodríguez Buenaño ${ }^{\text {b; }}$ Silva Ruth Suasnabas Pacheco ${ }^{c}$

Formación docente y el desarrollo del lenguaje en los niños y niñas del primer año de educación general básica

Revista Científica Mundo de la Investigación y el Conocimiento. Vol. 1 núm., 5, diciembre, 2017, pp. 147-162

DOI: 10.26820/recimundo/1.5.2017.147-162

Editorial Saberes del Conocimiento 


\section{Formación docente y el desarrollo del lenguaje en los niños y niñas del primer año de educación general básica}

Vol. 1, núm. 5., (2017)

Nadia del Rocío Campoverde Jiménez; María de Roció Rodríguez Buenaño; Silva Ruth Suasnabas Pacheco

\section{RESUMEN}

Las escuelas de la UTE 14 de la parroquia Ernesto Seminario del cantón Milagro, tiene problemas en el desarrollo del Lenguaje en los niños y niñas de primer año de Educación General Básica, causado por la poca actualización docente en estrategias metodológicas para su aprendizaje, refiriendo una relación directa entre la formación docente y el desarrollo del lenguaje en los niños. Esta investigación se fundamenta filosóficamente en el Empirismo, en lo pedagógico se sustenta en el método de María Montessori, el ámbito psicológico lo rige Jean Piaget, en lo sociológico las hermanas Agazzi son sus teorías la influencia para esta investigación, así mismo encuentra fundamentos legales en la Ley de Educación Superior y los estatutos de la Universidad. Este tema es de vital importancia, ya que el desarrollo del lenguaje es una de las bases fundamentales para el aprendizaje y desarrollo de destrezas en años posteriores, además de que en las escuelas que conforman la UTE 14, los niños y niñas de primer año de Educación General Básica no cumplen a cabalidad con el perfil de salida del año objeto de este estudio. La investigación fue de campo y se utilizaron las siguientes técnicas e instrumentos: entrevistas, encuesta y ficha de observación; dirigidas a los representantes legales, a los niños y niñas de primer año, así como a los docentes y directivos de la institución.

Palabras clave: Aprendizaje; formación; docente; niños; lenguaje. 


\title{
Formación docente y el desarrollo del lenguaje en los niños y niñas del primer año de educación general básica
} Vol. 1, núm. 5., (2017) Nadia del Rocío Campoverde Jiménez; María de Roció Rodríguez Buenaño; Silva Ruth Suasnabas Pacheco

\begin{abstract}
The UTE 14 schools of the Ernesto Seminario del Milagro canton, have problems in the development of the Language in the first-year children of General Basic Education, caused by the little updating of the teaching methodological strategies for their learning, referring to a direct relationship between teacher training and language development in children. This research is based philosophically on Empiricism, pedagogically based on the method of Maria Montessori, the psychological field is governed by Jean Piaget, in the sociological Agazzi sisters are his theories the influence for this investigation, likewise found legal grounds in the Law of Higher Education and the statutes of the University. This issue is of vital importance, since the development of language is one of the fundamental bases for learning and development of skills in later years, besides that in the schools that make up the UTE 14, the first-year children of Basic General Education do not fully comply with the exit profile of the year object of this study. The research was field and the following techniques and instruments were used: interviews, survey and observation card; addressed to legal representatives, to first-year children, as well as to teachers and directors of the institution.
\end{abstract}

Keywords: Learning; training; teacher; children; language. 


\section{Formación docente y el desarrollo del lenguaje en los niños y niñas del primer año de educación general básica}

Vol. 1, núm. 5., (2017)

Nadia del Rocío Campoverde Jiménez; María de Roció Rodríguez Buenaño; Silva Ruth Suasnabas Pacheco

\section{Introducción.}

El Ministerio de Educación en el sistema nacional de evaluación al Desempeño del estudiante, "pretende medir las actitudes y aptitudes del estudiante como respuesta al proceso educativo; es decir, las demostraciones de los conocimientos, habilidades, destrezas y valores desarrollados, como resultado del proceso educativo y su aplicación a la vida cotidiana”. (Ministerio de Educacion, 2012)

En nuestro país, desde 1996 hasta el año 2007, se han aplicado, en cuatro ocasiones, las pruebas APRENDO a los estudiantes de los años: tercero, séptimo y décimo de Educación Básica del sistema escolarizado, en las áreas de Matemática y Lenguaje y Comunicación. Estas pruebas se aplicaron de manera muestral y estuvieron fundamentadas en la Teoría Clásica de los Tests (TCT). (Peralvo Pico \& DT-Villena Chávez, 2013).

En este contexto, el Ministerio de Educación oficializó a partir del 4 de junio de 2008, la implementación de las pruebas SER ECUADOR, para la evaluación del desempeño de los estudiantes, con la adopción de una nueva metodología: la Teoría de Respuesta al Ítem (TRI) en el desarrollo de las pruebas de Logros Académicos y los cuestionarios de Factores Asociados. (Peralvo Pico \& DT-Villena Chávez, 2013).

Por primera vez se aplicó estas pruebas en el año 2008, de manera censal, a estudiantes de establecimientos educativos fiscales, fiscomisionales, municipales y particulares, en los años: cuarto, séptimo y décimo de Educación Básica, y tercero de Bachillerato, en las áreas de Matemática y Lenguaje y Comunicación, y se incluyó las áreas de Estudios Sociales y Ciencias 


\section{Formación docente y el desarrollo del lenguaje en los niños y niñas del primer año de educación general básica}

Vol. 1, núm. 5., (2017) Nadia del Rocío Campoverde Jiménez; María de Roció Rodríguez Buenaño; Silva Ruth Suasnabas Pacheco

Naturales, de manera muestral, en los años: séptimo y décimo de Educación Básica. (Borja, Manobanda, López, \& Bério, 2017)

Pruebas que fueron motivo de stress para los docentes debido a que se deseaba obtener el mejor desempeño posible, pero el modo de evaluación era superior a lo que se había enseñado a los estudiantes. Generando a la vez dos sentimientos, la decepción por el fracaso y la motivación a aprender a enseñar ese nuevo método evaluativo además claro está de lo cognitivo en todas las áreas de la educación.

Las evaluaciones al desempeño de estudiantes y docentes arrojaron cifras reales del estado de la educación en nuestro país, lo que lleva a la reflexión sobre la formación docente y sus repercusiones en la educación del Ecuador.

Este proceso de evaluación lleva adelante el Instituto Nacional de Evaluación Educativa (INEVAL) cuya misión es "Promover una educación de excelencia a través de la evaluación integral al Sistema Nacional de Educación y sus componentes" (Informte Ecuador, 2009), mediante la aplicación de evaluaciones confiables, objetivas, oportunas, pertinentes e imparciales y que toman como referencia los estándares de calidad educativa definidos por el Ministerio de Educación y enfocados en el aprendizaje de los estudiantes, amparados en la Constitución de la República en los artículos: 343, 344, 345 y especialmente en el artículo 346 que textualmente dice: "Existirá una institución pública, con autonomía de evaluación integral interna y externa, que promueva la calidad de la educación". (Asamblea Nacional, 2008) 


\section{Formación docente y el desarrollo del lenguaje en los niños y niñas del primer año de educación general básica}

Vol. 1, núm. 5., (2017)

Nadia del Rocío Campoverde Jiménez; María de Roció Rodríguez Buenaño; Silva Ruth Suasnabas Pacheco

Esta investigación es importante para los profesionales de la educación de primer año de educación básica, debido a que si bien es cierto que la educación es fundamental para la educación postrera, también lo es que se deben actualizar las estrategias para lograrlo y sobre todo recordar que lo que se pretende es que el niño aprenda a aprender, más que lo cognitivo de la enseñanza, pues esta será su mejor herramienta para su desempeño futuro.

Esta investigación tiene como objetivo identificar ¿Cuáles son las causas que fomentan un débil desarrollo del lenguaje en niños y niñas de primer año de Educación General Básica?, ¿Cómo mejorar el desarrollo lingüístico de estos niños y niñas?, ¿Cómo aportar a la formación docente parvularia?

Imagen $N^{\circ}$ 1: Parroquias Urbanas Municipalidad El Milagro 


\section{Formación docente y el desarrollo del lenguaje en los niños y niñas del primer año de educación general básica}

Vol. 1, núm. 5., (2017)

Nadia del Rocío Campoverde Jiménez; María de Roció Rodríguez Buenaño; Silva Ruth

Suasnabas Pacheco

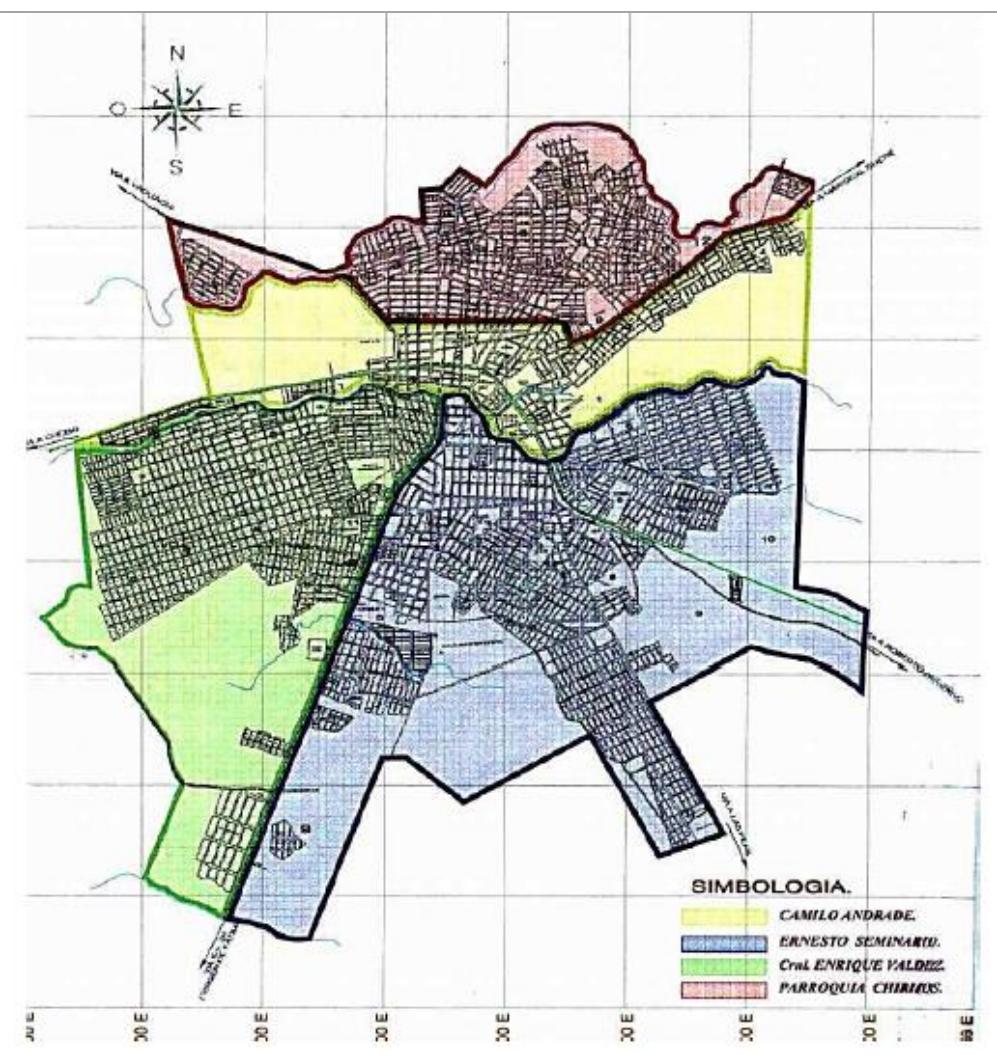

Fuente: (Ilustre Municipalidad del Milagro, 2011)

\section{Materiales y Métodos}

Para el desarrollo del estudio se tomó en cuenta el diseño de investigación como la planificación a seguir para el correcto desarrollo de la misma, sustentado en ello para este trabajo se consideraron las siguientes modalidades:

Por el lugar, de campo: puesto que se llevó a cabo en el lugar de los hechos, con los niños y niñas de primer año de Educación General Básica en las escuelas que conforman la UTE14,en la parroquia Ernesto Seminario del cantón Milagro, de la provincia del Guayas, en el año 2012. 


\section{Formación docente y el desarrollo del lenguaje en los niños y niñas del primer año de educación general básica}

Vol. 1, núm. 5., (2017)

Nadia del Rocío Campoverde Jiménez; María de Roció Rodríguez Buenaño; Silva Ruth Suasnabas Pacheco

Por el origen, bibliográfica: debido a que baso su contenido científico en libros, artículos, documentales web, u otros medios electrónicos.

Por el nivel de estudio, Descriptiva: porque se relacionó la información primaria y secundaria la misma que se midió para así describir la relación entre las variables que se investigó.

Correlacional: debido a que tiene como mira, determinar el grado de relación existente entre las variables integrantes de la investigación.

Por el propósito, aplicada: porque resolvió problemas prácticos encontrados en las escuelas de la parroquia Ernesto seminario, integrantes de la UTE 14.

Métodos de Investigación Los métodos empleados para el desarrollo del presente trabajo investigativo son los detallados a continuación:

Método empírico.- Este método está relacionado con la experiencia práctica, por lo tanto se ha tomado como instrumento o herramienta la observación directa; y mediante este punto de vista se ha obtenido información que permite establecer cómo mejorar el desarrollo del lenguaje de los niños y niñas de laUTE 14 de la parroquia Ernesto Seminario, cantón Milagro, provincia del Guayas.

Método inductivo.- permitió analizar casos particulares como son de otras instituciones en las que han usado la metodología lúdica a partir de los resultados que se han dado, se extrajeron conclusiones lo que permitió identificar cuáles son las bases que deben formar parte de esta propuesta. 


\section{Formación docente y el desarrollo del lenguaje en los niños y niñas del primer año de educación general básica}

Vol. 1, núm. 5., (2017) Nadia del Rocío Campoverde Jiménez; María de Roció Rodríguez Buenaño; Silva Ruth Suasnabas Pacheco

Método deductivo.- Ofreció la posibilidad de realizar un análisis sobre cada una de las causas que causan la problemática y en base a eso, concluir como mejorar el desarrollo del lenguaje de los niños de primer año de básica.

Método lógico.- Con la aplicación de este método se pudo dar una explicación mediante un análisis a la información obtenida con la aplicación de la encuesta, dando lugar a presentar las características que deben formar parte de la solución a la problemática encontrada.

Método Investigación - Acción.- La aplicación de este método permitió validar los resultados comprobados, para los que participaron en el proceso de investigación con la aplicación de las estrategias de cambio.

\section{Población}

Las unidades de análisis consideradas en esta investigación son los: padres de familia, las autoridades y docentes de las instituciones, todos integrantes de la comunidad educativa de la UTE 14, de la parroquia Ernesto Seminario.

Tabla $N^{\circ}$ 1: Población de Estudio

\begin{tabular}{|c|c|}
\hline Involucrados & Población \\
\hline Autoridades & 20 \\
\hline Docentes & 320 \\
\hline Padres de Familia & 12.800 \\
\hline Estudiantes & 12.800 \\
\hline
\end{tabular}


Formación docente y el desarrollo del lenguaje en los niños y niñas del primer año de educación general básica

Vol. 1, núm. 5., (2017)

Nadia del Rocío Campoverde Jiménez; María de Roció Rodríguez Buenaño; Silva Ruth Suasnabas Pacheco

\begin{tabular}{l|l|} 
Total & $\mathbf{2 5 . 9 4 0}$ \\
\hline
\end{tabular}

Fuente: Elaboración Propia.

\section{Muestra}

En un universo de trabajo en donde se desea aplicar un análisis estadístico, cuando el muestreo cubre a todos los elementos de la población., se realiza un censo. En muchos de los casos, la realización de un censo no es posible por ser muy costoso, muy extenso o que la muestra se destruya como resultado del análisis. En tales oportunidades se debe practicar un análisis muestral. La muestra es una parte seleccionada de la población que deberá ser representativa, es decir, reflejar adecuadamente las características que deseamos analizar en el conjunto en estudio. (Hernández Sampieri, Fernández Collado, \& Baptista Lucio, 2003)

Tabla $N^{\circ}$ 2: Muestra Calculada para el Estudio

\begin{tabular}{|c|c|c|c|}
\hline Involucrados & Población & Muestra & \% \\
\hline Autoridades & 20 & 4 & 1,37 \\
\hline Docentes & 320 & 32 & 10,95 \\
\hline Padres de Familia & 12.800 & 128 & 43,84 \\
\hline Estudiantes & 12.800 & 128 & 43,84 \\
\hline TOTAL & $\mathbf{2 5 . 9 4 0}$ & $\mathbf{2 9 2}$ & $\mathbf{1 0 0}$ \\
\hline
\end{tabular}

Fuente: Elaboración Propia.

\section{Resultados}




\section{Formación docente y el desarrollo del lenguaje en los niños y niñas del primer año de educación general básica}

Vol. 1, núm. 5., (2017) Nadia del Rocío Campoverde Jiménez; María de Roció Rodríguez Buenaño; Silva Ruth Suasnabas Pacheco

\section{Directores}

- La gran mayoría de directores, expresó su deseo de capacitar al personal docente a su cargo en estos talleres, pero confesó no haber logrado concretar ninguno, debido a sus múltiples responsabilidades, además alegaban estar a la espera de que el Ministerio de Educación, oferte esta actualización en el proyecto SIPROFE, donde están muy pendientes de inscribir a su personal.

- Los directores entrevistados recalcaron el cumplimiento parcial del perfil propuesto por el Ministerio de Educación, indicando que no es debido a no cumplir con el programa; sino más bien a la hiperactividad de la sociedad actual, donde los grupos de niños que ingresan año a año, ya no gozan del apoyo y estimulo ideal por parte de sus progenitores, recargan así la responsabilidad del desarrollo de destrezas y su desempeño real en los docentes.

- Las autoridades de las instituciones educativas exaltan los beneficios pedagógicos a obtenerse por los estudiantes, ya que su aprendizaje sería de un modo más eficiente y efectivo, al incluir nuevas actividades lúdicas y logopedia, acorde a nuestros tiempos al contar con el apoyo de la tecnología, aplicando las TIC en la educación.

- Los directores en su totalidad opinaron que el rendimiento en el desarrollo lingüístico sería el esperado por las autoridades del Ministerio de Educación en el perfil de salida de los niños de primer año de básica, con la aplicación de un manual de estrategias lingüísticas acorde a nuestros tiempos.

\section{Docentes}




\section{Formación docente y el desarrollo del lenguaje en los niños y niñas del primer año de educación general básica}

Vol. 1, núm. 5., (2017)

Nadia del Rocío Campoverde Jiménez; María de Roció Rodríguez Buenaño; Silva Ruth Suasnabas Pacheco

- Los docentes encuestados coinciden mayormente en que es de gran importancia el empleo de actividades lingüísticas en el aula para conseguir un desarrollo del lenguaje en los niños de primer año de Educación General Básica, con un 91\% de aceptación (63\%+28\%).

- Para la mayoría de docentes en un $81 \%$ opina que la autoestima de los niños está íntimamente ligada con el desarrollo del lenguaje. Mientras que un 16\% de la muestra tomada, encuentra que sólo a veces influye en su autoestima.

- Los docentes de la muestra, consideran que el diseño de un manual de estrategias lúdicas utilizado por los docentes permitirá un mejor desarrollo del lenguaje en los niños de primer año; no así un porcentaje menor de maestros que indica con la opción escogida que dudan que sea fundamental el diseño del mismo para el desarrollo lingüístico de los estudiantes de primer año de básica.

- Los docentes de la muestra concuerdan en un $100 \%$, en que el lenguaje es un medio de integración en sociedad, lo que se evidencia desde el aula de primer año de básica donde interactúan los niños entre sí, ejercitando el lenguaje en pleno desarrollo.

- Un índice elevado de docentes se muestra a favor de que la comunicación entre representantes legales y docentes fortalece el desarrollo del lenguaje en los niños, dividido entre un 47\% que piensa que siempre fortalece el desarrollo del lenguaje y un $37 \%$ que opina que frecuentemente lo fortalece. 


\section{Formación docente y el desarrollo del lenguaje en los niños y niñas del primer año de educación general básica}

Vol. 1, núm. 5., (2017) Nadia del Rocío Campoverde Jiménez; María de Roció Rodríguez Buenaño; Silva Ruth Suasnabas Pacheco

- La muestra de docentes encuestada está a favor en un $87 \%$ en que es necesario aplicar nuevas técnicas metodológicas para mejorar el desarrollo del lenguaje. Con el apoyo del 13\% de los docentes que opinan que frecuentemente son necesarias nuevas técnicas metodológicas.

\section{Representantes Legales}

- Un 97\% de representantes legales indica que el desarrollo del lenguaje es siempre la base para una buena educación, y un 3\% de los representantes se suma a este pensar afirmando que frecuentemente si es la base para una buena educación.

- El $100 \%$ de los representantes opina que el docente siempre debe motivar al niño para que obtenga un adecuado desarrollo del lenguaje a través de estrategias innovadoras.

- Para el $100 \%$ de los representantes, los docentes siempre deben aplicar estrategias de enseñanza eficientes que promuevan el desarrollo del lenguaje en los niños de primer año de Educación General Básica.

- Al igual que en ítems anteriores los representantes legales se manifiestan en un $100 \%$ de acuerdo en que los docentes deben recibir siempre capacitación para reforzar su formación docente.

- El mayor índice fue obtenido por los representantes que están de acuerdo en que su apoyo es siempre o frecuentemente fundamental para el avance en el desarrollo del lenguaje de los niños, con el $94 \%$ y $5 \%$; tan solo el $1 \%$ de representantes se muestra en duda pensando que sólo a veces ayuda en el desarrollo lingüístico de sus representados. 


\section{Formación docente y el desarrollo del lenguaje en los niños y niñas del primer año de educación general básica}

Vol. 1, núm. 5., (2017)

Nadia del Rocío Campoverde Jiménez; María de Roció Rodríguez Buenaño; Silva Ruth Suasnabas Pacheco

- Se puede deducir que la mayoría de representantes legales considera que se debe elaborar un manual de estrategias lingüísticas y ser actualizado siempre (93\%)o frecuentemente (6\%); sólo el 1\% de los representantes indicó que sólo debería elaborarse o actualizarse a veces.

\section{Conclusiones}

- Los directores de las instituciones educativas que conforman la UTE14 desean capacitar o actualizar los conocimientos de sus docentes en estrategias de aprendizaje.

- Los niños aprendientes de estas instituciones educativas hoy por hoy no cumplen completamente con el perfil propuesto por el Ministerio de Educación, debido a las estrategias metodológicas obsoletas aplicadas en estos grupos actuales de estudiantes.

- Los beneficios pedagógicos a obtenerse con los estudiantes al aplicar un manual de estrategias lingüísticas, son muchos ya que el desarrollo de su conciencia léxica, fonológica y semántica sería más eficiente y efectiva, al incluir nuevas actividades lúdicas y logopedia, acorde a nuestros tiempos al contar con el apoyo de la tecnología, y aplicar las TIC en la educación.

- El desempeño docente no es el idóneo, lo que se ve reflejado en la falta de seguridad en sus conocimientos; demostrando que la capacitación como refuerzo de su formación docente, influye en el mejoramiento de su desempeño profesional.

- La autoestima de los niños y niñas objeto de este estudio es baja por su deficiente desarrollo del lenguaje. Ya que el lenguaje es un medio de integración en sociedad, y en el aula de primer año de básica interactúan los niños entre sí, intentando en vano ejercitar su lenguaje en 


\section{Formación docente y el desarrollo del lenguaje en los niños y niñas del primer año de educación general básica}

Vol. 1, núm. 5., (2017) Nadia del Rocío Campoverde Jiménez; María de Roció Rodríguez Buenaño; Silva Ruth Suasnabas Pacheco

pleno desarrollo. Además al carecer de un adecuado desarrollo lingüístico difícultan el aprendizaje en años posteriores.

- Los docentes están dispuestos a la aplicación constante y permanente de un manual de estrategias lúdicas, que promueva nuevas técnicas metodológicas activas, con la certeza de que el mismo permitirá un mejor desarrollo del lenguaje en los niños de primer año.

- La comunicación entre representantes legales y docentes a pesar de que es sabido por los representantes que su apoyo fortalece el aprendizaje en sus representados en el desarrollo del lenguaje, no es el mejor, ya que no disponen de la información necesaria para ayudar a sus representados en el desarrollo de la lingüística y otras destrezas, para así fomentarla participación de los representantes en actividades de aula.

\section{Recomendaciones}

- Brindar la información necesaria a los representantes legales de los aprendientes de primer año de básica, sobre cómo reforzar lo aprendido en el salón de clases.

- Ofrecer a los niños y niñas objeto de esta investigación estímulo, mediante el uso de la lúdica y la logopedia en el salón de clase para el desarrollo de la conciencia léxica, semántica y fonológica.

- Diseño y aplicación inmediata de un manual de estrategias lingüísticas, que posea técnicas activas de aprendizaje; que dé lugar al refuerzo de la formación docente en estrategias 


\section{Formación docente y el desarrollo del lenguaje en los niños y niñas del primer año de educación general básica}

Vol. 1, núm. 5., (2017)

Nadia del Rocío Campoverde Jiménez; María de Roció Rodríguez Buenaño; Silva Ruth Suasnabas Pacheco

metodológicas activas para el desarrollo del lenguaje, donde se incluyan talleres de promoción del apoyo y estímulo paterno.

- Intensificación de gestiones, para la obtención de materiales didácticos que faciliten la aplicación de estrategias lingüísticas con metodología activa, en el desarrollo del lenguaje.

\section{Bibliografía}

Informte Ecuador. (2009). Obtenido de http://informateecuador.com/resultados-ser-bachiller/ Asamblea Nacional. (2008). Constitución de la República del Ecuador. Quito: Registro Oficial.

Borja, R. V., Manobanda, M., López, J., \& Bério, F. (2017). European Scientific Journal. Obtenido de https://eujournal.org/index.php/esj/article/view/10057

Hernández Sampieri, R., Fernández Collado, C., \& Baptista Lucio, P. (2003). Metodología de la investigación (Vol. 707). Mexico: McGraw-Hill.

Ilustre Municipalidad del Milagro. (21 de 12 de 2011). Tierra Dulce. Obtenido de http://www.milagro.gob.ec/sitio/historia.html

Ministerio de Educacion. (2012). Estandádres de Calidad Cducativa. Quito.

Peralvo Pico, Y. M., \& DT-Villena Chávez, D. (2013). Repositorio Universidad Técnica de Ambato. Recuperado el 17 de 12 de 2017, de http://repositorio.uta.edu.ec/bitstream/123456789/4340/3/Mg.DCEv.Ed.1820\%20pdf 